\title{
Rigid-Core Oligothiophene-S,S-dioxides with High Photoluminescence Efficiencies Both in Solution and in the Solid State
}

\author{
Giovanna Barbarella,* Laura Favaretto, and Giovanna Sotgiu \\ Consiglio Nazionale Ricerche, I.Co.C.E.A, Via Gobetti 101, 40129 Bologna, Italy \\ Luciano Antolini \\ Dipartimento di Chimica, Università di Modena e Reggio Emilia, Via Campi 183, \\ 41100 Modena, I taly \\ Giuseppe Gigli and Roberto Cingolani \\ I stituto Nazionale di Fisica della Materia, Dipartimento Ingegneria Innovazione, \\ Università di Lecce, Via Arnesano, 73100 Lecce, I taly

\begin{abstract}
Alessandro Bongini
Dipartimento di Chimica G. Ciamician, Università di Bologna, Via Selmi 2, 40126 Bologna, I taly
\end{abstract}

Received May 1, 2001. Revised Manuscript Received J uly 9, 2001

\begin{abstract}
The photoluminescence $(P L)$ frequencies and quantum efficiencies of dithieno[3,2-b;2',3'd]thiophene-4,4-dioxide (1), its 3,5-dimethyl derivative (2), and the corresponding 4-oxide (3) are reported and discussed in relation to their single-crystal X-ray structures. The peculiar packing modalities of dioxides $\mathbf{1}$ and $\mathbf{2}$, based on dimeric units originated by short S... $\mathrm{O}$ contacts between molecules related by an inversion center, cause an unusually high bathocromic shift of PL frequencies from solution to solid state. This effect is accompanied by a marked decrease in solid-state PL efficiencies (12\% and $16 \%$ ) compared to those in solution (75\% and $77 \%$ ). In monoxide 3 the loss of local symmetry inherent to the change $\mathrm{SO}_{2} \rightarrow$ SO deeply modifies the self-assembly and PL properties, and the PL efficiency in the solid state is close to that in solution. Ab initio calculations on the ground and excited states of compound $\mathbf{1}$ were performed and compared to those of a conformationally mobile counterpart. Oligomers containing dithienothiophene $\mathbf{2}$ as internal core were synthesized and found to be characterized by high PL efficiencies in the solid-state (up to 48\%) as well as in solution (up to $85 \%$ ). The current-voltage and luminance-voltage plots of an electroluminescent diode fabricated with one of these new rigid-core oligothiophene-S,Sdioxides are reported.
\end{abstract}

\section{Introduction}

Organic light emitting diodes (OLEDs) based on small molecules or polymers are currently the object of wide interest from a scientific and technological point of view, and new exciting developments on materials, device structure, tuning of light emission frequencies, thin-film deposition methods, etc. have been achieved. ${ }^{1}$

Parallel to the developments aimed to rapid industrial applications, new research is required to elucidate the fundamental relationships existing between the molecular structure of organic materials, their supramolecular organization in the solid state, and their photoluminescence $(P L)$ and electrol uminescence $(E L)$ properties. A deeper understanding of this matter is indeed a prerequisite to improve and eventually optimize materials and devices.

\footnotetext{
* Corresponding author. E-mail: barbarella@area.bo.cnr.it.
}

It is generally assumed that, owing to statistical factors, only a quarter of all excited states of organic materials are singlet type, from which fluorescence may occur, and in consequence EL efficiencies $\left(\eta_{\mathrm{EL}}\right)$ are related to PL efficiencies ( $\eta_{\mathrm{PL}}$ ) by the relationship: $\eta_{\mathrm{EL}}$ $\leq 1 / 4 \eta_{\mathrm{PL}}{ }^{1,2}$ The $E L$ efficiencies measured in OLEDs are generally much lower than this upper limit, because of problems inherent to device fabrication, such as inefficient charge injection at the metal electrodes, bad filmability of the material, coupling-out factors. Thus, a stringent requirement for thin film electroluminescent devices to display reasonably high efficiencies is that they are based on materials characterized by high PL quantum yields in the solid state. ${ }^{1,2}$

PL efficiencies are the result of a delicate balance between radiative and nonradiative decay patterns from singlet excited state to ground state, following UV excitation. In the solid-state this balance is largely 
affected by molecular self-assembly modalities, which may cause intermolecular interactions, leading to photoluminescence quenching, or govern conformational changes favoring specific nonradiative mechanisms. ${ }^{3}$ In dilute solution, aggregation forces are less compelling and the photol uminescence behavior is more dependent on the intrinsic electronic features of the molecules. ${ }^{3,4}$

Recently, remarkable results in terms of solid-state PL efficiencies have been achieved with thiophene-based polymers and oligomers, indicating that these chemically very stable compounds are not only useful for application in field-effect transistors ${ }^{5}$ but also in electroluminescent devices. ${ }^{6}$

Polythiophenes containing phenyl groups on the backbone have been shown to display solid-state photoluminescence quantum yields up to nearly $30 \%$. Lightemitting diodes from blue to near-infrared have been fabricated, some of which display high el ectroluminescence efficiencies. ${ }^{6}$

Oligothiophenes display in general appreciably high photoluminescence quantum yields in solution, which increase on increasing the oligomer size (up to $40-50 \%$ for the hexamer) but drop by several orders of magnitude in the solid state. ${ }^{3 c}$ However, we have recently shown that the insertion of one thienyl-S,S-dioxide unit into the backbone of oligothiophenes may lead to solidstate photoluminescence efficiencies as high as 37\%, increased electron affinities, and much greater photo-

(1) (a) Sheats, J . R.; Antoniadis, H.; Hueschen, M.; Leonard, W.; Miller, J .; Moon, R.; Roitman, D.; Stocking, A. Science 1996, 273, 884. (b) Baldo, M. A.; O'Brien, D. F.; You, Y.; Shoustikov, A.; Sibley, S.; Thompson, M. E.; Forrest, S. R. Nature 1998, 395, 151. (c) Leising, G.; Tasch, S.; Graupner, W. In Handbook of conductive polymers; Skotheim, T. A., Elsenbaumer, R. L., Reynolds, J. R., Eds.; Marcel Dekker: New York, 1998; p 847. (d) Kraft, A.; Grimsdale, A. G.; Holmes, A. B. Angew. Chem., Int. Ed. Engl. 1998, 37, 402. (e) Burrows, P. E.; Bulovic, V.; Gu, G.; Kozlov, V.; Forrest, S. R.; Thompson., M. E. Thin Solid Films 1998, 331, 101. (f) Cao, Y.; Parker, I. D.; Yu, G.; Zhang, C.; Heeger, A. J. Nature 1999, 397, 414. (g) Martin, R. E. Diederich., F. Angew. Chem., Int. Ed. Engl. 1999, 38, 1350. (h) Deshpande, R. S.; Bulovic, V.; Forrest, S. R. Appl. Phys. Lett. 1999, 75, 888. (i) Yu, W. L.; Cao, Y.; Pei, J .; Huang, W.; Heeger, J. A. Appl. Phys. Lett. 1999, 75, 3270. (I) Stössel, M.; Staudigel, J .; Simmerer, J :; Winnacker, A. Appl. Phys. A 1999, 68, 387. (m) Ho, P. K. H.; Kim, J. S.; Burroughes, J. H.; Becker, H.; Li, S. F. Y.; Brown, T. M.; Cacialli, F.; Friend, R. H. Nature 2000, 404, 481. (n) Gross, M.; Muller, D. C. Nothofer, H. G.; Scherf, U.; Neher, D.; Brauchle, C.; Meerholz. K. Nature 2000, 405, 661. (o) Müllen, K.; Wegner, G., Eds. Electronic Materials: The Oligomer Approach; Wiley-VCH: New York, 1998. (p) Miyata, S.; Nalwa, H. S., Eds. Organic Electroluminescent Materials and Devices: Gordon and Breach Publishers: Amsterdam, 1997.

(2) Mitschke, U.; Bäuerle, P. J. Mater. Chem. 2000, 10, 1471.

(3) (a) J enekhe, S. A.; Osaheni. J. A. Science 1994, 265, 765. (b) J akubiak, R.; Collison, C. J : Wan, W. C.: Rothberg. L. I I Phys. Chem. A 1999, 103, 2394. (c) Oelkrug, D.; Egelhaaf, H. J .; Gierschner, J .; Tompert, A. Synth. Met. 1996, 249. (d) Yang, A.; Kuroda, M.; Shiraishi, Y.; Kobayashi, T. J. Chem. Phys. 1998, 109, 8442. (e) Van Hutten, P F.; Krasnikov, V. V.; Hadziioannou, G. Acc. Chem. Res. 1999, 32, 257. (f) J akubiak, R.; Collison, C. J .; Wan, W. C.; Rothberg, L. J J J Phys. Chem. A 1999, 103, 2394. (g) DiCésare, N.; Belletête, M.; Garcia, E. R.; Leclerc, M.; Durocher, G. J . Phys. Chem. A 1999, 103, 3864. (h) Beljonne, D.; Cornil, J .; Friend, R. H.; J ansen, R. A. J .; Brédas, J . L. J. Am. Chem. Soc. 1996, 118, 6453. (i) Cornil, J .; dos Santos, D. A.; Crispin, X.; Silbey, R.; Bredas, J . L. J . Am. Chem. Soc. 1998, 120, 1289 (I) Brédas, J . L.; Cornil, J .; Beljonne, D.; Dos Santos, D. A.; Shuai, Z. Acc. Chem. Res. 1999, 32, 267.

(4) (a) Chosrovian, H.; Rentsch, S.; Grebner, D.; Dahm, U.; Birckner, E. Synth. Met. 1993, 60, 23. (b) Kanemitsu, Y.; Suzuki, K.; Masumoto Y.; Tomiuchi, Y.; Shiraishi, Y.; Kuroda, M. Phys. Rev. B 1994, 50, 2301.

(5) (a) Garnier, F. Acc. Chem. Res. 1999, 32, 209. (b) Katz, H. E.; Laquindanum, J. G.; Lovinger, A. J . Chem. Mater. 1998, 10, 633.

(6) (a) Andersson, M. R.; Thomas, O.; Mammo, W.; Svensson, M.; Theander, M.; Inganäs, O. J . Mater. Chem. B 1999, 9, 1933.(b) Gigli, G.; Barbarella, G.; F avaretto, L.; Cacialli, F.; Cingolani, R. Appl. Phys. Lett. 1999, 75, 439. (c) Pei, J .; Yu, W. L.; Huang, W.; Heeger, A. J . Macromolecules 2000, 33, 2462.
Scheme 1. Synthetic Pattern for the Preparation of Compounds 2, 3, 5, and $6^{a}$

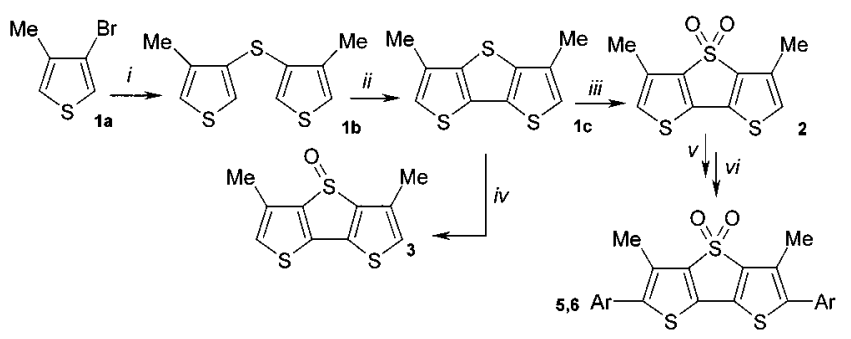

a (i) BuLi/Et $2 \mathrm{O},\left(\mathrm{PhSO}_{2}\right)_{2} \mathrm{~S}$; (ii) BuLi/Et $\mathrm{H}_{2} \mathrm{O}, \mathrm{CuCl}_{2}$; (iii) acetic acid, $\mathrm{H}_{2} \mathrm{O}_{2}$; (iv) $\mathrm{BF}_{3} \cdot \mathrm{Et}_{2} \mathrm{O} / \mathrm{CH}_{2} \mathrm{Cl}_{2} / \mathrm{MCPBA}$; (v) NBS/acetic acid, $\mathrm{CH}_{2} \mathrm{Cl}_{2}$; (vi) $\mathrm{ArSnBu} /$ /toluene, $\mathrm{Pd}\left(\mathrm{AsPh}_{3}\right)_{4} ; \mathrm{Ar}=$ phenyl (5) and 3-methylthiophene (6).

stability. ${ }^{7 a, c}$ With some of these oligomers efficient LEDs were also fabricated, emitting light in a wide range of colors. ${ }^{6,7 a}$

Conformationally mobile oligothiophene-S,S-dioxides display extremely low PL efficiencies in solution and high PL efficiencies in the solid state, a behavior just opposite to that of conventional thiophene oligomers. ${ }^{7 a}$ Nevertheless, in these compounds, a change of solvent from chloroform to Decalin leads to a marked increase in PL. ${ }^{7 b}$ Since it is known that the PL quantum yield of flexible molecules may increase greatly in high-viscosity media (such as Decalin), ${ }^{8}$ this result suggests that conformational mobility plays an important role in determining the PL properties of oligothiophene-S,Sdioxides in solution and possibly even in the solid state when facile torsional displacements in the excited state are allowed.

We report here the synthesis and the photol uminescence properties of 3,5-dimethyldithieno[3,2-b;2', $\left.3^{\prime}-d\right]$ thiophene-4,4-dioxides and of oligomers containing this unit as an internal rigid core. We show that the presence of the rigid core leads to a dramatic increase of PL in solution and results in ol igomers displaying high photoluminescence efficiencies both in solution and in the solid state. The data are interpreted with the aid of ab initio theoretical calculations and single-crystal X-ray data and by means of the comparison with the X-ray structure and the optical properties of a rigid dithienothiophene-S-oxide. Finally, the electroluminescence characteristics of a diode fabricated with one of the new oligomers are described.

\section{Results}

Scheme 1 shows the synthetic pattern followed for the synthesis of 3,5-dimethyldithieno[3,2-b;2, 3'-d]thiophene4,4-dioxide (2), of the corresponding 4-oxide $\mathbf{3}$, and of the "rigid-core oligomers" $\mathbf{5}$ and $\mathbf{6}$, starting from commercial 3-bromo-4-methylthiophene.

(7) (a) Barbarella, G.; Favaretto, L.; Sotgiu, G.;Zambianchi, M.; Fattori, V.; Cocchi, M.; Cacialli, F.; Gigli, G.; Cingolani, R. Adv. Mater. 1999, 11, 1375-1379. (b) Antolini, L.; Tedesco, E.; Barbarella, G. Favaretto, L.; Sotgiu, G.; Zambianchi, M.; Casarini, D.; Gigli, G.; Cingolani, R. J. Am. Chem. Soc. 2000, 122, 9006. (c) Barbarella, G.; Favaretto, L.; Sotgiu, G.; Zambianchi, M.; Bongini, A.; Arbizzani, C.; Mastragostino, M.; Anni, M.; Gigli, G.; Cingolani, R. J . Am. Chem. Soc. 2000, 122, 11971. (d) Barbarella, G.; Zambianchi, M.; Sotgiu, G.; Bongini, A. Tetrahedron 1997, 53, 9401.

(8) (a)Waldeck, D. H. Chem. Rev. 1991, 91, 415. (b) Bridges, J . W. In Luminescence in Chemistry; Bowen, E. J ., Ed.; London, 1970; p 84. 
Table 1. Absorption ( $\lambda_{\mathrm{abs}}, \mathrm{nm}$ ) and Photoluminescence $\left(\lambda_{\mathrm{PL}}, \mathrm{nm}\right)$ Wavelengths and Photoluminescence Quantum Yields $(\eta \%)^{a}$ of Compounds $1-4$ in Solution ${ }^{b}$ and as Microcrystalline Powders ${ }^{c}$

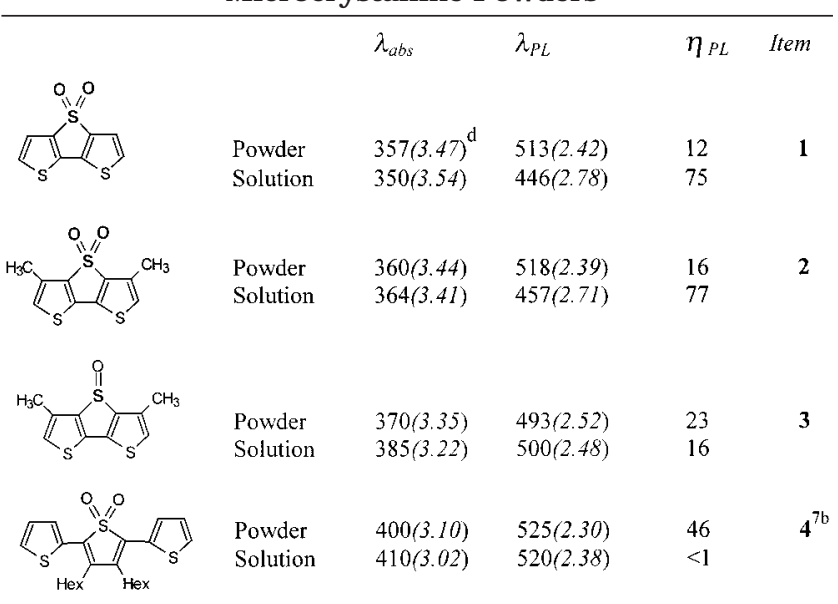

a Absolute values measured with an integrating sphere under irradiation at $\lambda_{\text {exc }}=363 \mathrm{~nm} .{ }^{b} \mathrm{CH}_{2} \mathrm{Cl}_{2}$. ${ }^{c}$ Very similar quantum yields were obtained for spin-coated films from chloroform solutions. ${ }^{d}$ Values in parentheses are in eV.

The synthetic pattern for the preparation of compound $\mathbf{2}$ is similar to that al ready described for the synthesis of the unsubstituted precursor $\mathbf{1}^{9}$ (Table 1 ).

Direct oxidation of the thienyl ring to the corresponding S-oxide is generally difficult and only a few thienylS-oxides have been described so far. ${ }^{10-12}$ Neverthel ess, we have been able to obtain 3,5-dimethyldithieno[3,2b;2', 3'-d]thiophene-4-oxide 3 from the corresponding dithienothiophene by using the methodology described by Furukawa et al. ${ }^{10}$

Compound 2 can easily be brominated at the terminal positions. The reaction of the dibromo derivative with the appropriate thienyl or phenyl stannane in the presence of palladium(0) catalysts ${ }^{13}$ affords longer "rigidcore" oligomers in good yields. On changing the nature of the stannane employed in the reaction, the emission wavevelength of these longer oligomers can be tuned across the entire visible range in much the same way as we have already described for conformationally mobile ol igothi ophene-S,S-dioxides. ${ }^{7 \mathrm{C}}$ In this paper, only the synthesis and the optical properties of two selected oligomers of this type $(\mathbf{5 , 6})$ are reported.

The properties of compounds $\mathbf{1}-\mathbf{3}$ are described in section I while those of oligomers $\mathbf{5 , 6}$ are described in section II.

(I) Photoluminescence Properties, Ab Initio Calculations, and X-ray Structures of Compounds 1-3. (a) Photol uminescence Properties. The maximum wavelength absorptions $\left(\lambda_{\max }\right)$ and emissions $\left(\lambda_{\mathrm{PL}}\right)$ and the absolute PL quantum yields ( $\eta_{\mathrm{PL}}$ ) under UV irradiation $\left(\lambda_{\text {exc }}=363 \mathrm{~nm}\right)$ of compounds $\mathbf{1}-\mathbf{3}$ in solution and in the solid-state are shown in Table 1. For comparison, the $\lambda_{\max }, \lambda_{\mathrm{PL}}$, and $\eta_{\mathrm{PL}}$ values of the conformationally mobile trimer $\mathbf{4}^{\text {7b }}$ are also reported. The table shows in

(9) De J ong, F.; J anssen, M. J . J . Org. Chem. 1971, 36, 1645.

(10) Furukawa, N.; Zhang, S.; Sato, S.; Higaki, M. Heterocycles 1997, $44,61$.

(11) J iang, B.; Don Tilley, T. J . Am. Chem. Soc. 1999, 121, 9744.

(12) Bongini, A.; Barbarella, G.; Zambianchi, M.; Arbizzani, C.; Mastragostino, M. Chem. Commun. 2000, 439.

(13) Barbarella, G.; Favaretto, L.; Sotgiu, G.; Zambianchi, M.; Antolini, L.; Pudova, O.; Bongini, A. J . Org. Chem. 1998, 63, 5497. parentheses the energies corresponding to the measured wavelengths.

In solution, large Stokes shifts (up to $0.7 \mathrm{eV}$ ) from absorption to emission wavelengths are observed for all compounds, in agreement with those reported for conformationally mobile oligothi ophene-S,S-dioxides. ${ }^{7}$ The emission wavelengths are in the deep blue region for all compounds. The $\eta_{\mathrm{PL}}$ values of dioxides $\mathbf{1}$ and $\mathbf{2}$ are remarkably high and greater than that of monoxide $\mathbf{3}$.

In the solid state, the maximum absorption wave lengths are near those in solution for all compounds. This is not the case for the emission wavelengths, since only for 3 is $\lambda_{\mathrm{PL}}(500 \mathrm{~nm})$ near that in solution $(493 \mathrm{~nm})$. For dioxides 1 and 2, the $\lambda_{\mathrm{PL}}$ values (513 and $518 \mathrm{~nm}$, respectively) are markedly higher than those in solution (446 and $457 \mathrm{~nm}$ ). Moreover, for both compounds, an energy difference of $1.05 \mathrm{eV}$ between absorption and emission wavelengths is observed, much larger than that found in solution and also much larger than that measured for monoxide $\mathbf{3}$ in the solid state $(0.83 \mathrm{eV})$.

The solid-state PL quantum yields, $\eta_{\mathrm{PL}}$, of dioxides $\mathbf{1}$ and $\mathbf{2}(12 \%$ and $16 \%)$ are significantly lower than those in sol ution (75\% and $77 \%$ ). It is worth noting, however, that even if much lower than those maesured in solution, the PL quantum yields of $\mathbf{1}$ and $\mathbf{2}$ are still high compared to those of conventional oligothiophenes of comparable or larger size in the solid state. ${ }^{3 \mathrm{c}}$ Contrary to the case with $\mathbf{1}$ and $\mathbf{2}$, the solid-state $\eta_{\mathrm{PL}}$ value of monoxide $3(23 \%)$ is slightly greater than that measured in solution $(16 \%)$.

The absorption and emission wavelengths of the conformationally mobile trimer $\mathbf{4}$ in the solid state are near those in solution, while the shift in energy from absoption to emission amounts to $0.80 \mathrm{eV}$ in the solid state and to $0.64 \mathrm{eV}$ in solution. ${ }^{7 \mathrm{~b}}$ The $\eta_{\mathrm{PL}}$ value of $\mathbf{4}$ is high in the solid state (46\%) but drops to less than $1 \%$ in solution. ${ }^{7 b}$ However, if the solution is frozen in liquid nitrogen, an intense yellow light emission is observed under UV irradiation, which decreases progressively in intensity as the solid melts.

(b) Theoretical Calculations. The geometries of the excited states of organic molecules may be different from that of the ground state. I ndeed, the excited states may display distortions from the ground-state geometry in order to achieve greater stability. Distortion processes are favored in conformationally mobile molecules.

Dioxides $\mathbf{1}$ and $\mathbf{2}$ (dimers for the number of carboncarbon bonds, trimers for the number of sulfur atoms) have the same type of molecular symmetry as trimer $\mathbf{4}$ in the all-trans configuration (the most stable one, as shown by theoretical data and X-ray structures ${ }^{7 b}$ ).

To verify whether the mobility of $\mathbf{4}$ around the $\mathrm{C}-\mathrm{C}$ bonds next the oxygenated moi ety leads to different excited-state geometry compared to those of the fused systems 1 and 2, we have carried out ab initio 6-31G* calculations on $\mathbf{1}$ and on trimer TOT (the same as $\mathbf{4}$ except for the hexyl chains), employing the ab initio correlation method $\mathrm{Cl}$-Singles. This method uses only combinations of single substitutions and has been described to give an adequate treatment for excited states. ${ }^{14}$ The results of the calculations relative to the first excited state are shown in Scheme 2.

(14) Exploring Chemistry with Electronic Structure Methods, 2nd ed.; Foresman, J . B., Frisch, EE., Eds.; Gaussian Inc.: Pittsburgh, PA, 1996; p 213. 
Table 2. Summary of Crystal Data Collection and Structure Refinement of Compounds 1-3

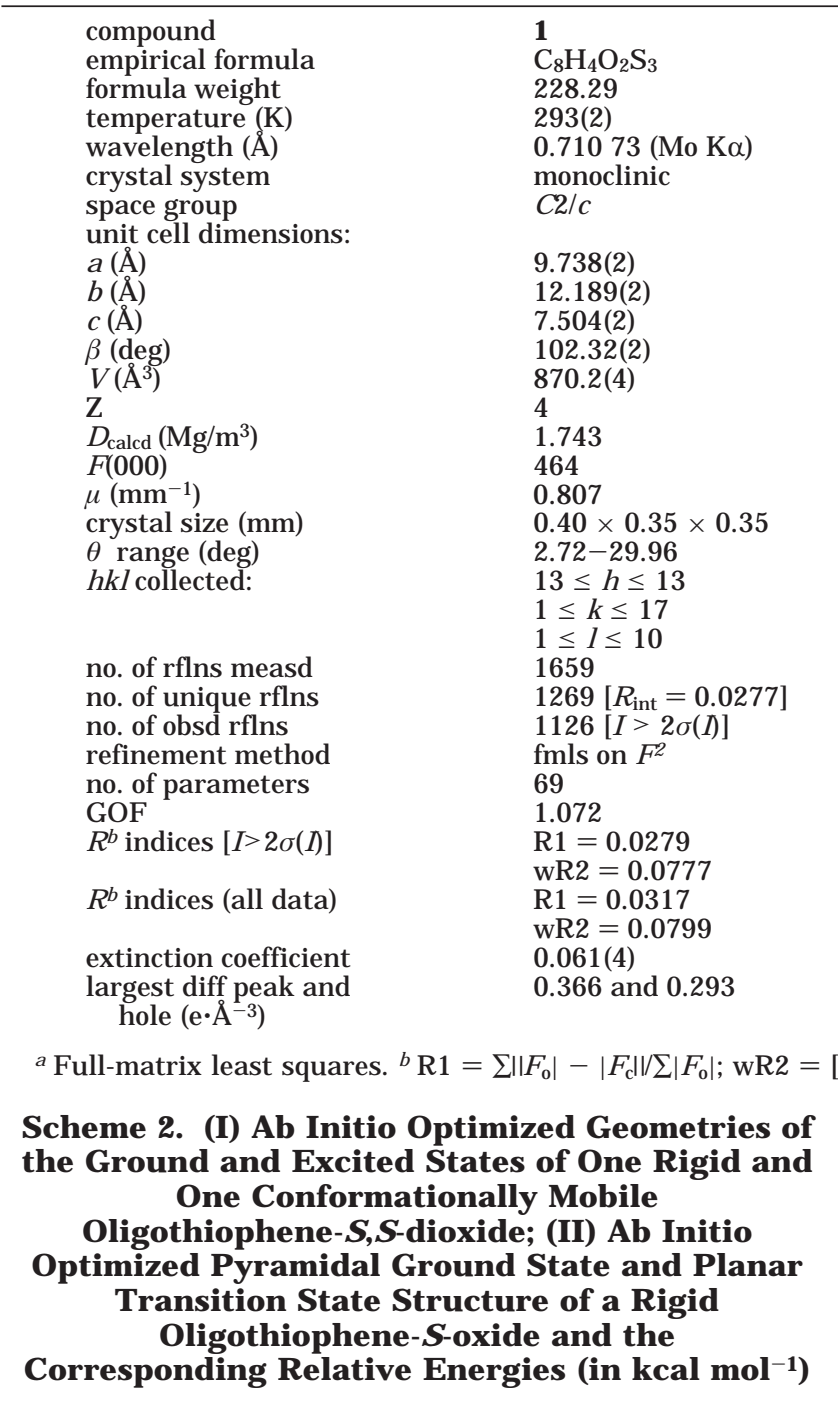

I)
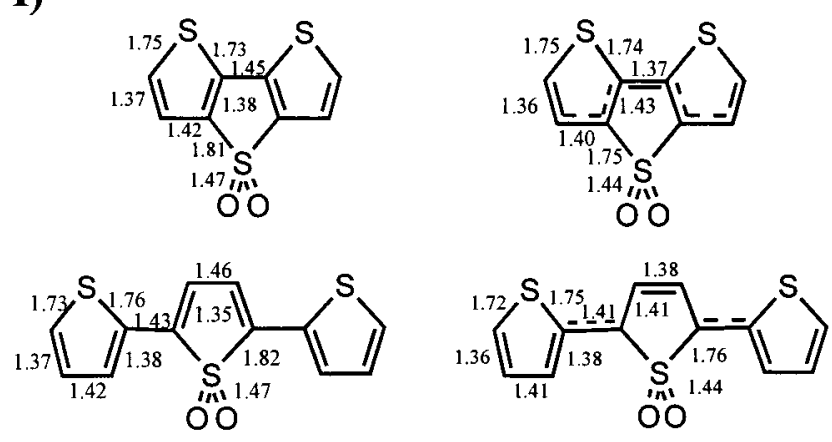

II)

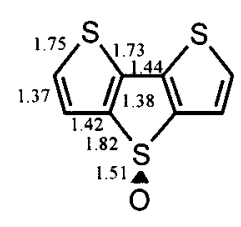

0

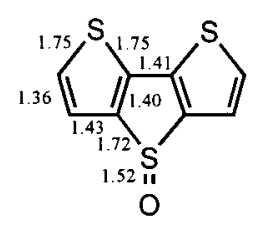

29.6
For the determination of the ground-state geometries, also shown in Scheme 2, electron correlation by means of the hybrid density functional B $3 L Y^{15}$ has been included.

Scheme 2 (top) shows that the geometrical changes for the rigid system on passing from the ground to the

\begin{tabular}{|c|c|}
\hline $\begin{array}{l}2 \\
\mathrm{C}_{10} \mathrm{H}_{8} \mathrm{O}_{2} \mathrm{~S}_{3} \\
256.34 \\
293(2) \\
0.71073(\mathrm{Mo} \mathrm{K} \alpha) \\
\text { monoclinic } \\
\mathrm{P} 21 / \mathrm{n}\end{array}$ & $\begin{array}{l}3 \\
\mathrm{C}_{10} \mathrm{H}_{8} \mathrm{OS}_{3} \\
240.34 \\
293(2) \\
0.71073(\mathrm{Mo} \mathrm{K} \alpha) \\
\text { monoclinic } \\
\mathrm{P} 21 / \mathrm{n}\end{array}$ \\
\hline $\begin{array}{l}7.378(1) \\
12.238(2) \\
12.382(3) \\
102.27(2) \\
1092.5(4) \\
4 \\
1.559 \\
528 \\
0.652 \\
0.35 \times 0.32 \times 0.25 \\
2.37-29.95 \\
10 \leq \mathrm{h} \leq 10 \\
1 \leq \mathrm{k} \leq 17 \\
1 \leq 1 \leq 10 \\
3874 \\
3169\left[\mathrm{R}_{\text {int }}=0.0350\right] \\
2337[1>2 \sigma(\mathrm{I})] \\
\text { fmls on F2 } \\
164 \\
1.034 \\
\mathrm{R} 1=0.0365 \\
\text { WR2 }=0.1046 \\
\mathrm{R} 1=0.0555 \\
\text { wR2 }=0.1129 \\
\end{array}$ & $\begin{array}{l}11.377(2) \\
8.064(1) \\
12.030(2) \\
107.46(1) \\
1052.8(3) \\
4 \\
1.516 \\
496 \\
0.664 \\
0.45 \times 0.40 \times 0.35 \\
2.16-29.97 \\
15 \leq \mathrm{h} \leq 15 \\
1 \leq \mathrm{k} \leq 11 \\
1 \leq 1 \leq 16 \\
3910 \\
3065\left[\mathrm{R}_{\text {int }}=0.0115\right] \\
2743[1>2 \sigma(\mathrm{I})] \\
\text { fmls on } \mathrm{F}^{2} \\
156 \\
1.047 \\
\mathrm{R} 1=0.0271 \\
\text { wR2 }=0.0807 \\
\mathrm{R} 1=0.0307 \\
\text { wR2 }=0.1129 \\
0.064(3)\end{array}$ \\
\hline and 0.382 & 0.531 and 0.340 \\
\hline
\end{tabular}

0.345 and 0.382

$\left.\mathrm{F}^{2}\right)^{2} /\left[W\left(\mathrm{Fo}_{\mathrm{o}}^{2}\right)^{2}\right]^{1 / 2}$

excited state are remarkably similar to those of the mobile counterpart. The variations concern essentially the central oxygenated unity and are in agreement with an increased quinoid character of both molecules in the excited state.

ZINDO/S calculations on ab initio geometries predict a large red shift from absorption to emission wavelengths. The calculated values for $\lambda_{\max }$ are 368 and 412 $\mathrm{nm}$ for $\mathbf{1}$ and TOT, respectively. The calculated values for $\lambda_{\mathrm{PL}}$ of 1 and TOT are 425 and $479 \mathrm{~nm}$, respectively. The trend is in agreement with the values measured for compounds $\mathbf{1}$ and $\mathbf{4}$.

Finally, we have carried out ab initio B $3 L$ Y P calculations on the ground-state geometry of a rigid dithienothiophene-S-oxide (the equivalent of $\mathbf{3}$ without the methyl substituents; see Scheme 2, bottom). The calculations predict a nonplanar ground-state structure for this compound, with the sulfur atom lying $0.19 \AA$ under the plane formed by the two thienyl rings and the oxygen atom lying $0.93 \AA$ above the same plane. According to the calculations, sulfur pyramidal inversion proceeds through a fully planar transition state with a calculated energy barrier of $29.6 \mathrm{kcal} / \mathrm{mol}$. This value is almost twice that calculated for thiophene-1-oxide, ${ }^{12}$ showing that the rigidification of the system increases markedly the energy barrier to sulfur pyramidal inversion.

(c) X-ray Structures. The molecular structures of compound 1, 2, and $\mathbf{3}$ are shown in Figures 1-3, along with atom numbering schemes and drawings of their crystal packing motifs. Selected structural dimensions are reported in Tables 2 and 3.

(15) Becke, A. D. J . Chem. Phys. 1993, 98, 5648. 

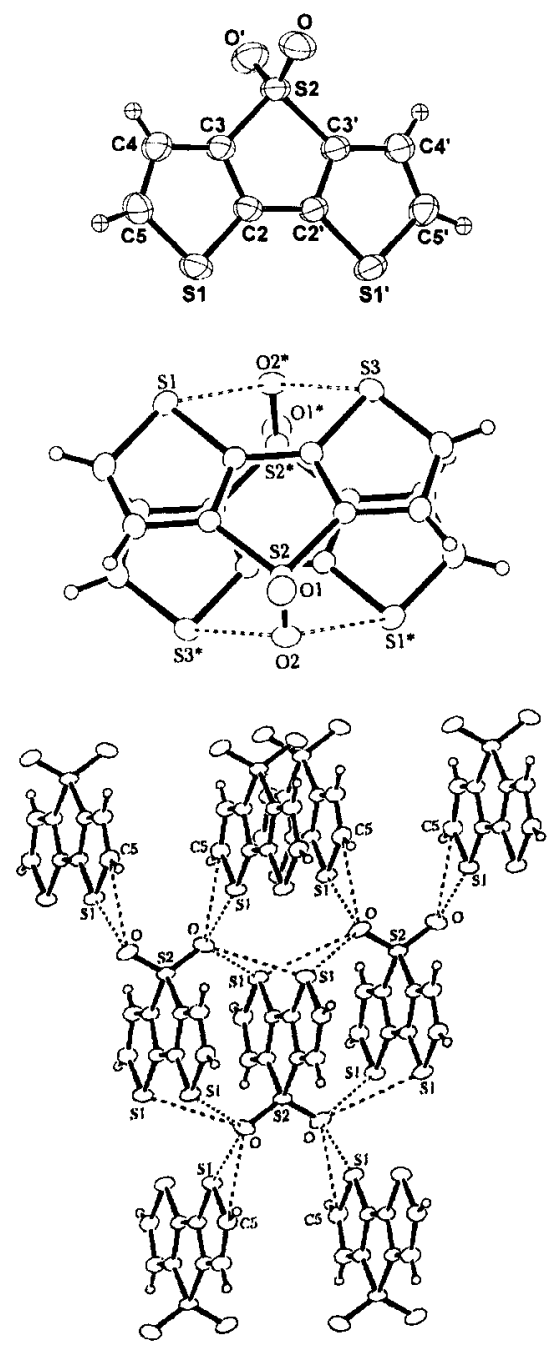

Figure 1. Crystal structure and molecular packing of compound $\mathbf{1}$. Thermal ellipsoids enclose $60 \%$ probability. Equivalent atoms are related by a 2-fold axis.

Compound 1 possesses precise (i.e. crystallographically dictated) $\mathrm{C}_{2}$ symmetry, the 2 -fold axis passing through the $\mathrm{S} 2$ atom and the midpoint of the $\mathrm{C} 2-\mathrm{C}^{\prime}$ bond. Excluding the oxygens atoms, the molecule is fully coplanar, with atomic deviations from mean plane not exceeding $0.008 \AA$.

The dimensions and conformation of compound $\mathbf{2}$ are exactly the same as those of $\mathbf{1}$. The most significant difference is the lack of a crystallographic 2-fold axis, despite a nearly idealized $C_{2}$ symmetry. The $C$ and $S$ atoms of $\mathbf{2}$ are slightly less coplanar than in $\mathbf{1}$, with a maximum atomic deviation of $0.059 \AA$.

Most of the corresponding bond distances and angles in $\mathbf{1}$ and $\mathbf{2}$ do not differ more than one or two estimated standard deviations, and their values compare very well with those previously observed in other fused-ring and $\alpha-\alpha^{\prime}$ conjugated oligothiophenes. ${ }^{16-21}$

(16) Bertinelli, F.; Palmieri, P.; Stremmenos, C.; Pelizzi, G.; Taliani, C. J. Phys. Chem. 1983, 87, 2317.

(i7) Li, X.-C.; Sirringhaus, H.; Garnier, F.; Holmes, A. B.; Moratti, S. C.; Feeder, N.; Clegg, W.; Teat, S. J .; Friend, R. H. J . Am. Chem. Soc. 1998, 120, 2206.

(18) Catellani, M.; Destri, S.; Porzio, W. Acta Crystallogr. Sect. C 1988, 44, 545. 596.

(19) Catellani, M.; Porzio, W. Acta Crystallogr. Sect. C 1991, 47,
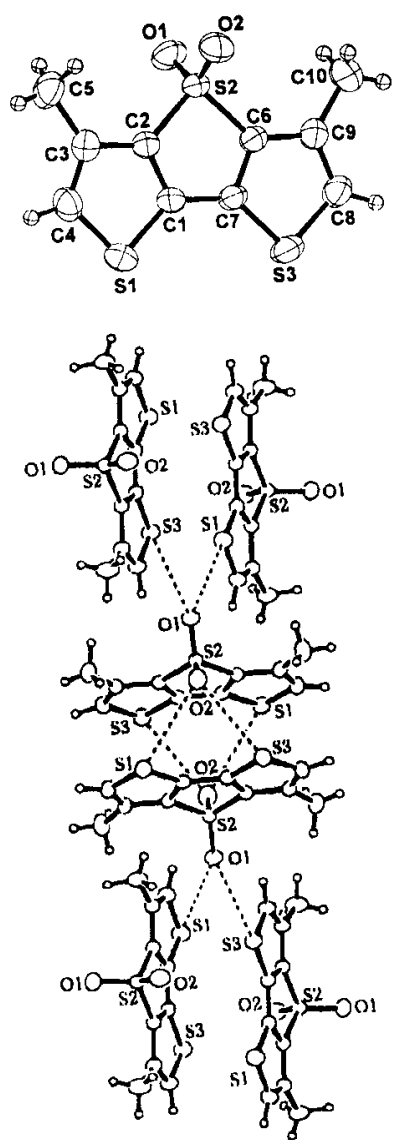

Figure 2. Crystal structure and molecular packing of compound 2.

The S-oxide 3 displays approximate $\sigma$ symmetry, and its ring atoms are coplanar within $\pm 0.031 \AA$. This compound shows marked lengthening of all bond distances involving the S (thienyl-S-oxide) atom, which displays acute pyramidal geometry, as al ready observed for other thienyl-S-oxides. ${ }^{11}$ On the contrary, the dimensions of outer rings compare very well with those observed in $\mathbf{1}$ and $\mathbf{2}$ (Table 3).

The crystal packing of $\mathbf{1}-\mathbf{3}$ exhibits interesting and somewhat unexpected features.

In both dioxides, the molecules are tied in complex tridimensional networks of short and even extremely short nonbonded contacts, occurring mainly between sulfonic $\mathrm{O}$ and thienyl $\mathrm{S}$ atoms. Basically, the crystal packing can be visualized as being built up of dimeric units, arising from four short $\mathrm{S}$-..O contacts between molecules related by inversion center and hence parallel (Figure 1). One oxygen atom acts as a bridge between two thienyl sulfurs of the parallel molecule, with S...O separations ranging from 3.361(1) to 3.498(2) A. These dimeric units interact with other neighboring mol ecules in a completely different way for the two dioxides.

Because of symmetry requirements, all molecules of $\mathbf{1}$ pack in the crystal in parallel planes, and its dimeric units stack, with equal spacing, in a direction perpendicular to the mean molecular plane, forming parallel

(20) Barbarella, G.; Zambianchi, M.; Antolini, L.; Ostoja, P.; Maccagnani, P.; Bongini, A.; Marseglia, E. A.; Tedesco, E.; Gigli, G.; Cingolani, R. J . Am. Chem. Soc. 1999, 121, 8920.

(21) Antolini, L.; Tedesco, E.; Barbarella, G.; Favaretto, L.; Sotgiu, G.; Zambianchi, M.; Casarini, D.; Gigli, G.; Cingolani, R.J . Am. Chem. Soc. 2000, 122, 9006. 
Table 3. Summary of Relevant Structural Features of Compounds 1-3

\begin{tabular}{|c|c|c|c|}
\hline compound & 1 & 2 & 3 \\
\hline \multirow[t]{4}{*}{$C-S(\AA)$ in outher rings } & $1.701(1)$ & $1.706(2)$ & $1.706(1)$ \\
\hline & $1.715(2)$ & $1.715(2)$ & $1.725(2)$ \\
\hline & $1.701(1)^{a}$ & $1.702(2)$ & $1.704(1)$ \\
\hline & $1.715(2)^{a}$ & $1.718(2)$ & $1.720(1)$ \\
\hline \multirow[t]{2}{*}{$\mathrm{C}-\mathrm{S}(\AA)$ in inner ring } & $1.763(1)$ & $1.762(2)$ & $1.787(1)$ \\
\hline & $1.763(1)^{\mathrm{a}}$ & $1.762(2)$ & $1.791(1)$ \\
\hline \multirow{2}{*}{$\mathrm{S}-\mathrm{O}(\AA)$} & $1.440(1)$ & $1.433(1)$ & $1.497(1)$ \\
\hline & $1.440(1)^{\mathrm{a}}$ & $1.437(1)$ & \\
\hline max out of plane $(\AA)$ of ring atoms & $0.008(1)$ & $0.045(1)$ & $0.031(1)$ \\
\hline \multirow[t]{2}{*}{ out of plane $(\AA)$ of $\mathrm{O}$ atoms } & $1.224(1)$ & $1.117(2)$ & $1.249(1)$ \\
\hline & \multicolumn{3}{|c|}{ shortest intermolecular contacts $(\AA)$ : } \\
\hline O‥S & $3.263(1)$ & $3.298(2)$ & $3.197(1)$ \\
\hline $\mathrm{O} \cdots \mathrm{C}$ & $3.264(2)$ & $3.342(3)$ & $3.291(2)$ \\
\hline S...S & $3.8750(5)$ & $3.6709(8)$ & $3.4716(7)$ \\
\hline no. of probable $\mathrm{CH}$...O bonds & 1 & 2 & \\
\hline dihedral angles (deg) between & $180^{\mathrm{a}}$ & $77.09(3)$ & $56.52(2)$ \\
\hline
\end{tabular}

a Due to crystallographic symmetry requirements.

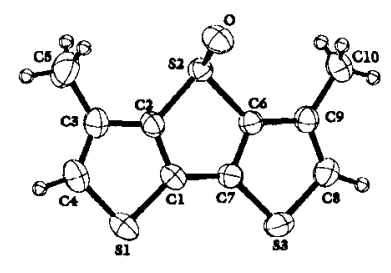

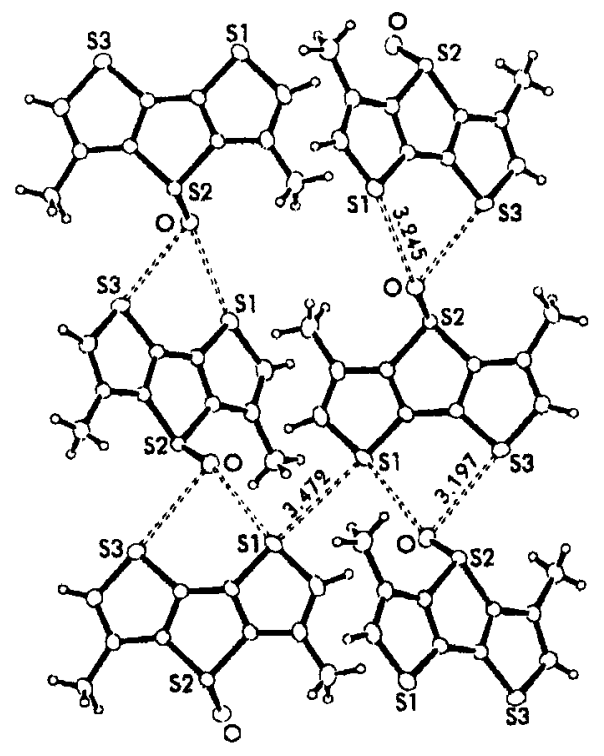

Figure 3. Crystal structure and molecular packing of compound 3.

columns (Figure 1). A number of short S $\cdots 0$ [from 3.263(1) to 3.458(1) $\AA$ ] and C...O [from 3.264(2) to 3.579(2) $\AA$ ] contacts occur between parallel columns. The shortest $\mathrm{C} \cdots \mathrm{O}$ one is probably consistent with a weak $\mathrm{C}-\mathrm{H} \ldots \mathrm{O}$ hydrogen bond, with a subtended angle at the $\mathrm{H}$ atom of $124(2)^{\circ}$.

In compound $\mathbf{2}$, despite the steric hindrance of the methyl substituents and a noncoplanar packing mode, the number and shortness of intermolecular contacts are quite close to those in $\mathbf{1}$. In this case, the $\mathrm{O}$ atom not involved in interactions between centrosymmetric molecules makes short contacts with the thienyl $\mathrm{S}$ of two different pairs of S...O doubly bridged molecules (F igure 2). The mean planes between dimers related by screw axis (or glide plane) make a dihedral angle of 77.09(3) ${ }^{\circ}$. Like in $\mathbf{1}$, also in compound $\mathbf{2}$ the shortest C...O contact
[3.342(3) A] is probably consistent with a weak hydrogenbonding interaction, with a subtended angle of $120(2)^{\circ}$. It seems likely that the loss of crystallographic $C_{2}$ symmetry in compound $\mathbf{2}$ is due to its short van der Waals contacts.

Despite the presence of only one higly polarized $\mathrm{O}$ atom, compound $\mathbf{3}$ forms a very compl ex tri di mensi onal network of short intermolecular contacts, even shorter than those in dioxides $\mathbf{1}$ and $\mathbf{2}$. It is worth noting that in this case the molecules interact also through very short S...S contacts (Table 3), quite rarely observed in oligothiophene derivatives.

Finally, it may be outlined that all compounds exhibit extremely rigid molecular frameworks with unusually Iow atomic thermal parameters. As a result, the crystals are good diffracting up to very high $\theta$ Bragg angles, and the quality of the diffraction data allowed us to obtain surprisingly good crystallographic reliability indices (Table 2).

(II) Photo and Electroluminescence Properties of Oligomers 5 and 6 . The maximum absorption $\left(\lambda_{\max }\right)$ and emission $\left(\lambda_{\mathrm{PL}}\right)$ wavelengths and the absolute PL quantum yields $\left(\eta_{\mathrm{PL}}\right)$ under UV irradiation $\left(\lambda_{\mathrm{exc}}=363\right.$ $\mathrm{nm}$ ) of compounds $\mathbf{5}$ and $\mathbf{6}$ in solution and in the solid state are shown in Table 4.F or comparison, the $\lambda_{\max } \lambda_{\mathrm{PL}}$, and $\eta_{\mathrm{PL}}$ values of the conformationally mobile pentamers $\mathbf{7}^{7 \mathrm{a}}$ and $\mathbf{8}^{\mathrm{7c}}$ are also reported.

In solution, the energy shift from absorption to emission amounts to $0.7-0.8 \mathrm{eV}$ for both compounds, as found in the case of compounds $\mathbf{1 - 3}$ in the same solvent.

In the solid state, for both $\mathbf{5}$ and $\mathbf{6}$ the energy shift from absorption to emission amounts again to $0.7-0.8$ eV; i.e., it is the same as that measured in solution. This result underlines the peculiarity of the behavior of compounds $\mathbf{1}$ and $\mathbf{2}$ in the solid state, for which an energy shift $>1$ eV was measured (see above).

In solution, the PL quantum yield of both $\mathbf{5}$ and $\mathbf{6}$ (tetramers for the number of carbon atoms, pentamers for the number of sulfurs) is $85 \%$, i.e., more than 2 orders of magnitude greater than that measured for the conformationally mobile pentamers 7 and $\mathbf{8}(<1 \%) .{ }^{7 a, c}$ To our knowledge, this is the highest PL efficiency value ever reported for "all-thienyl" oligomers (5) in solution. 
Table 4. Absorption ( $\lambda_{\mathrm{abs}}, \mathrm{nm}$ ) and Photoluminescence $\left(\lambda_{\mathrm{PL}}, \mathrm{nm}\right)$ Wavelengths and Photoluminescence Quantum Yields $(\eta \%)^{a}$ of Compounds 5-8 in Solution ${ }^{b}$ and as Microcrystalline Powders ${ }^{c}$

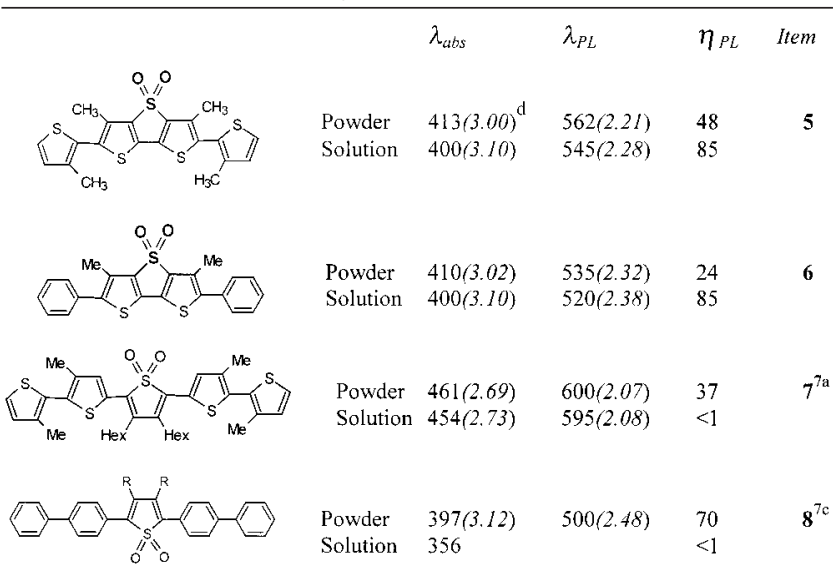

a Absolute values measured with an integrating sphere under irradiation at $\lambda_{\text {exc }}=363 \mathrm{~nm} .{ }^{b} \mathrm{CH}_{2} \mathrm{Cl}_{2}$. ${ }^{\mathrm{c}}$ Very similar quantum yields were obtained for spin-coated films from chloroform solutions. ${ }^{d}$ Values in parentheses are in $\mathrm{eV}$.

In the solid state, the PL efficiencies of $\mathbf{5}$ and $\mathbf{6}, 48 \%$ and $24 \%$, respectively, are smaller than those measured in solution, as in the case of $\mathbf{1 , 2}$. Nevertheless, the $\eta_{\mathrm{PL}}$ value measured for $\mathbf{5}$ is the highest measured so far for oligothiophene-S,S-dioxides. Compound $\mathbf{5}$ is also the first case in which an "all-thienyl" oligomer displays greater PL efficiency than that of a corresponding mixed thienylene-phenylene one (6). Indeed, so far, for conformationally mobile oligothiophene-S,S-dioxides containing phenyl groups on the backbone, solid-state quantum yields much greater than those of the corresponding "all-thienyl" systems have been measured.7c

All oligothiophene-S,S-di oxides are characterized by high electron affinities and ionization energies, as deduced from the redox potentials measured by cyclovoltammetry. $22 a, b$ This is also the case for compounds 1,2, 5, and 6. Thus, for example, oligomer 4 shows reversible reduction and oxidation peak potentials at $-1.51 \mathrm{~V}$ and $+1.22 \mathrm{~V}$ (VS SCE), ${ }^{22 c}$ respectively, in agreement with the values measured for oligothiopheneS,S-dioxides of comparable size.

The high electron affinities of oligothiophene-S,Sdioxides and their high solid-state PL efficiencies make these compounds suitable for the fabrication of electroluminescent devices. $6 c, 7 a$ Moreover, these oligomers have good filmability characteristics and films of good quality can be prepared by spin-coating.

An electroluminescent device was fabricated using compound $\mathbf{5}$ as the active emissive material evaporation (see scheme on the top of Figure 4). Compound 5 was spin-coated onto an indium tin oxide (ITO) substrate on which a film of poly(3,4-ethylenedioxy)thiophene (PEDOT), doped with polystyrene sulfonate, had al ready been deposited. ITO acted as the anode (hole injecting) while the cathode (Ca/Al, el ectron injecting) was deposited by thermal evaporation. The device displayed a diode-like behavior with a very low turn-on voltage

(22) (a) Barbarella, G.; Favaretto, L.; Zambianchi, M.; Pudova, O. Arbizzani, C.; Bongini, A.; Mastragostino, M. Advanced Materials 1998 10, 551. (b) Barbarella, G.; Favaretto, L.; Sotgiu, G.; Zambianchi, M.; Arbizzani, C.; Bongini, A.; Mastragostino, M. Chem. Mater. 1999, 11 2533. (c) Arbizzani, C.; Mastragostino, M., private communication.
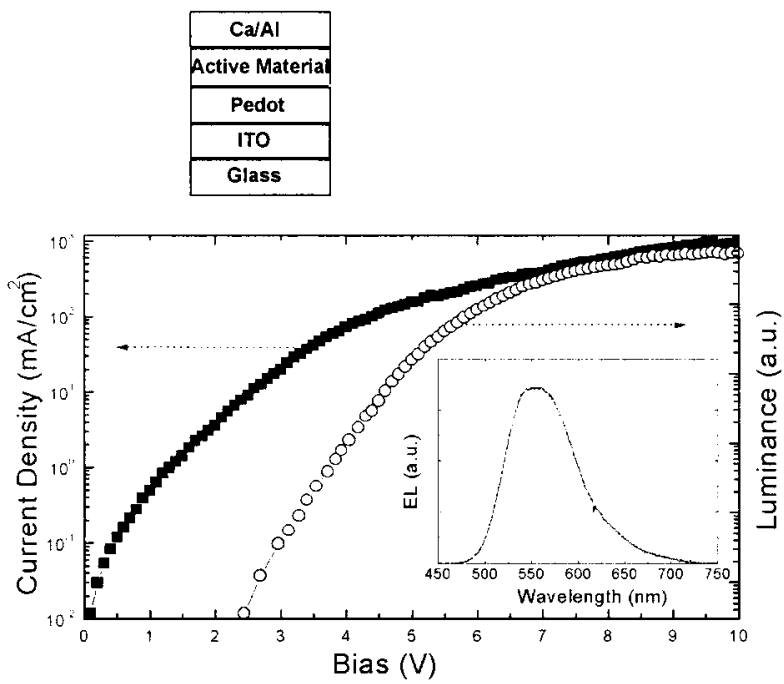

Figure 4. Current-voltage and luminance-voltage plot of the electroluminescent diode fabricated with compound 5. The inset shows the electroluminescence spectrum. The scheme on the top shows the configuration of the device.

(about $2.5 \mathrm{~V}$ ). The current-vol tage/luminance-voltage plot obtained for this two-layer device is displayed in Figure 4, the inset of which shows the electroluminescence spectrum of $5\left(\lambda_{\mathrm{EL}}=550 \mathrm{~nm}\right)$. The maximum luminance value measured for this device was $110 \mathrm{~cd} /$ $\mathrm{m}^{2}$, while the external electroluminescence efficiency was $0.004 \%$, much lower than that measured for the device fabricated with the conformationally mobile compound 7.7a

\section{Discussion}

The rigid-core oligothiophene-S,S-dioxides described here are the first class of thiophene oligomers displaying high photoluminescence efficiencies both in solution and in the solid state.

Our data show that fusing the thienyl-S,S-dioxide moiety to the adjacent thienyl rings and then blocking its torsional movements increase the PL efficiencies in solution by more than 2 orders of magnitude, jumping from $<1 \%$ to $75-85 \%$ (compare $\mathbf{2}$ with $\mathbf{4}, \mathbf{5}$ with 7, and 6 with 8 in Tables 1 and 4). The phenomenon is reminescent of what occurs, for example, in conformationally mobile phenolphthalein, which is nonfluorescent, when it is transformed into the rigid analogue fluorescein, which is one of the most important fluorescent markers for biomolecules. ${ }^{8 b}$

Clearly, the very low PL efficiencies measured in solution for conformationally mobile ol igothiophene-S,Sdioxides is mainly caused by excited-state coupling with vibrorotational quanta generated by the torsional movements of the $\mathrm{C}-\mathrm{C}$ bonds next the oxygenated moiety. This also explains why most oligomers containing one central thienyl-S,S-dioxide moiety display high PL quantum yields in the solid state, where torsional movements are frozen. ${ }^{7 b, c}$

According to these results, in oligothiophene-S,Sdioxides the main nonradiative pathway for energy relaxation from the excited to the ground state is internal conversion (IC) rather than intersystem crossing (ISC) as in conventional thiophene ol igomers. ${ }^{3 h, i, 4}$ Support for this assumption comes also from prelimi- 
nary results on time-dependent PL measurements ${ }^{23}$ and from comparison with literature data. For example, the $\mathrm{PL}$ efficiency of quaterthiophene in chloroform increases only from $17 \%$ to $24 \%$ when the presence of methylene bridges or other kinds of torsional constraints block the rotations of the bithiophene subsystems, ${ }^{24}$ indicating that in conventional oligothiophenes geometric constraints to free rotation of the thienyl rings have scarce impact on PL efficiencies in solution.

From our results one can also infer that in oligothiophene-S,S-dioxides the lowest singlet excited state is mainly localized on the oxygenated moiety. Indeed, comparison of the PL efficiency of $\mathbf{5}$ with that of $\mathbf{2}$ shows that when additional sources of torsional movements are made available by increasing the ol igomer size only minor changes occur in $\eta_{\mathrm{PL}}$. Further support for this assumption comes from ZINDO/S cal culations, according to which the LUMO of oligothiophene-S,S-dioxides is mainly concentrated on the oxygenated moiety, whereas the LUMO of the corresponding conventional thiophene ol igomers is more dispersed along the entire aromatic backbone.22b

On the whole, the present data confirm that the functionalization of the thienyl sulfur is a method of choice to engineer the optical properties of thiophene oligomers. However, there are many possible ways for the functionalization of thienyl sulfur to occur, including the functionalization to S-oxide instead of S,S-dioxide, ${ }^{10-12}$ and it is of main interest to know how different functionalization types affect the electronic and optical properties.

Thienyl-S-oxides have been scarcely studied so far, mainly due to synthetic difficulties. Contrary to the thienyl-S,S-dioxide moiety, which is no longer aromatic, the thienyl-S-oxide moiety has still some aromatic character, and the electronic and electrochemical properties of thiophene-S-oxide are intermediate between those of thiophene and thiophene-S,S-di oxide. ${ }^{12}$ To our knowledge, nothing has been reported so far on the PL properties of these kinds of compounds.

The rigid thienyl-S-oxide 3, whose optical properties are shown in Table 1, is photoluminescent both in solution and in the solid state. However, its $\eta_{\mathrm{PL}}$ value in solution (16\%) is much smaller than that of the corresponding S,S-dioxide 2 (77\%), although greater than that of conventional thiophene oligomers of comparable size. ${ }^{3 c}$ One could object that since the $\mathrm{S}-\mathrm{O}$ group is pyramidal, at room temperature very rapid pyramidal inversion might be a facile nonradiative deactivation channel causing the lowering of PL efficiency. Ab initio calculations of the energy barrier to sulfoxide pyramidal inversion in $\mathbf{3}\left(29.6 \mathrm{kcal} \mathrm{mol}^{-1}\right.$; see Scheme 2) rule out this possibility. Apparently, thienylS-oxides are intrinsically less efficient light emitters than the corresponding thienyl-S,S-dioxides. In our view, these data suggest that the PL properties of thienyl-S-oxides are intermediate between those of thienyl and thienyl-S,S-dioxides and that this in some way is related to the progressively decreasing aromatic

(23) Cerullo, G.; Lanzani, G.; Zavelani-Rossi, M.; De Silvestri, S.; Barbarella, G.; Sotgiu, G. Synth. Met. 2001, 119, 617.

(24) Benicori, T.; Bongiovanni, G.; Botta, C.; Cerullo, G.; Lanzani, G.; Mura, A.; Rossi, L.; Sannicolo', F.; Tubino, R. Phys. Rev. B 1998, 58, 9082. nature when passing from thienyl to thienyl-S-oxide to thienyl-S,S-dioxide. The answer can only come from theoretical calculations (a very complex matter when excited states are involved), but our experimental data point in this direction.

Before commenting on solid-state PL efficiencies, let us examine the self-assembly properties of compounds 1-3 as deduced from single-crystal X-ray data.

The main forces that drive self-assembly modalities and conformation in conventional thiophene oligomers in the solid state are $\mathrm{CH} \cdots \pi$ and $\mathrm{CH} \cdots \mathrm{S}$ intra- and intermolecular interactions. ${ }^{25,26}$ In conformationally mobile oligothiophene-S,S-dioxides, these kinds of interactions are still very important and counteract the di polar forces introduced by the presence of the sulfonyl group, the final balance depending on oligomer size. As the number of thienyl units attached to the oxygenated moiety increases, the molecules become progressively more planar and tend to pack in parallel layers. This may cause photoluminescence quenching. ${ }^{7 b}$ In the rigid compounds 1-3, the lack of conformational flexibility leads to the dominance of intra- and intermolecular forces related to the presence of the oxygen atoms. As shown in Table 3, all structures are characterized by very short S... $\mathrm{O}$ and $\mathrm{C} \ldots \mathrm{O}$ contacts and the self-assembly modalities are very different from those already described for conventional oligothiophenes or conformationally mobile oligothiophene-S,S-dioxides.

The S,S-dioxide $\mathbf{1}$ forms dimeric units where one oxygen atom acts as a bridge between two thienyl sulfurs of the parallel molecule, and these units stack according to a nice columnar structure (F igure 1). When passing from $\mathbf{1}$ to $\mathbf{2}$, the presence of the methyl groups (needed to ensure good solubility) is insufficient to prevent the formation of the dimeric units, which, however, pile in a completely different manner, forming a large dihedral angle between the mean planes of dimeric units related by screw axis (Figure 2). When passing from 2 to 3 , the lack of local symmetry caused by the prencence of only one single oxygen on sulfur has an even more dramatic effect on self-assembly properties. There is no more formation of dimeric units, and the molecules pack in a very complex and tight structure, much like a tridimensional polymeric network, still based on very short S $\cdots \mathrm{O}, \mathrm{C} \cdots \mathrm{O}$, and $\mathrm{S} \cdots \mathrm{S}$ contacts (Figure 3 and Table 3).

The different self-assembly modalities have a remarkable impact on the PL properties of $\mathbf{1 - 3}$ in the solid state.

Table 1 shows that the $\eta_{\mathrm{PL}}$ values of dioxides $\mathbf{1}$ and $\mathbf{2}$ drop from $75 \%$ and $77 \%$ in solution to $12 \%$ and $16 \%$ in the solid state. Visual inspection of the peculiar packing modalities of these compounds (Figures 1 and 2) suggests that excimer ${ }^{3 a}$ formation might be the cause of this dramatic drop of PL efficiencies from solution to solid state. Excimer formation has in fact already been demonstrated for small molecules characterized by a supramolecular organization based on cofacial sandwichtype configurations with interplanar distances of 3-4

(25) Marseglia, E. A.; Grepioni, F.; Tedesco, E.; Braga, D. Mol . Cryst. Liq. Cryst 2000, 348, 137.

(26) Barbarella, G.; Zambianchi, M.; Antolini, L.; Ostoja, P.; Maccagnani, P.; Bongini, A.; Marseglia, E. A.; Tedesco, E.; Gigli, G.; Cingolani, R. J . Am. Chem. Soc. 1999, 121, 8920-8926. 
$\AA$, $3 \mathrm{a}$ similar to that shown by $\mathbf{1}$ and $\mathbf{2}$ in the solid state. Moreover, the formation of excimers, which are generally poorly emissive states, decreases the photoluminescence quantum yields and increases the emission wavelengths. ${ }^{3 a}$ The decrease in PL efficiency of $\mathbf{1}$ and $\mathbf{2}$ from solution to the solid state is indeed accompanied by a bathocromic shift of the emission wavelength, which is much larger than that observed for all the other compounds (>1-1.2 eV vs $0.6-0.8 \mathrm{eV})$. The large bathocromic shift from absorption to emission of $\mathbf{1}$ and $\mathbf{2}$ in the solid state causes a change in color of the emitted light from deep blue in solution to greenishyellow in the solid state. On the contrary, under UV irradiation, compound $\mathbf{3}$ displays a nice light-blue emission in solution that remains blue in the solid state. As shown in Figure 3, there is no dimer formation in the solid-state structure of this compound, and the red shift from emission to absorption wavelengths in the solid state $(0.8 \mathrm{eV})$ is cl ose to that measured in solution (0.6 eV). F urthermore, the PL quantum yield displayed by 3 in the solid state (23\%) is even greater than that in solution (16\%). Thus, the data relative to compound $\mathbf{3}$ support the hypothesis of excimer formation in $\mathbf{1}$ and 2. Nevertheless, we are aware of the fact that time- and concentration-dependent PL measurements are needed to confirm this hypothesis, but this is beyond the aim of the present work.

Passing from dimer $\mathbf{2}$ to tetramer $\mathbf{5}$, the $\eta_{\mathrm{PL}}$ increases up to the quite remarkable value of $48 \%$, the highest sol id-state photoluminescence efficiency ever measured for an "all-thienyl" oligomer. Unfortunately, we were not able to obtain single crystals of suitable quality for this compound. However, following our line of interpretation, this result means that the presence of the methyl groups in head-to-head arrangement prevents the molecules from becoming planar and leads to less tight packing and reduced intermolecular interactions. Head-to-head regiochemistry has already been shown to favor high PL values in polythiophenes. ${ }^{27}$

The el ectroluminescent diode fabricated using oligomer $\mathbf{5}$ as the emissive material displayed an external el ectroluminescence efficiency of $0.004 \%$. This value is rather low in absolute terms ${ }^{2}$ and also in comparison with the $E L$ efficiencies obtained with other oligothiophene-S,S-dioxides of larger size, ${ }^{6 c, 7 a, 29}$ but it is high if one takes into account that $\mathbf{5}$ is a short oligomer and that many electroluminescent diodes fabricated with conventional thiophene oligomers and polymers display comparable and even lower EL efficiencies. ${ }^{2,6 a, 28}$ Better quality films could probably improve the electroluminescence efficiency of the device. As with most oligothiophene-S,S-dioxides, $\mathbf{5}$ is characterized by high photostability, and the device reported in Figure 4 operated in air without appreciable changes for a few hours, attaining a maximum luminance value of $110 \mathrm{~cd} / \mathrm{m}^{2}$. Although luminance values on the order of several thousand $\mathrm{cd} / \mathrm{m}^{2}$ have been obtained with the best materials reported so far, ${ }^{2}$ it should not be ignored that

(27) Barta, P.; Cacialli, F.; Friend, R. H.; Zagorska, M. J . Appl. Phys. $1998,84,6279$

(28) Väterlein, C.; Neureiter, H.; Gebauer, W.; Ziegler, B.; Sokolowski, M.; Bäuerle, P.; U mbach, E. J. Appl. Phys. 1997, 82, 3003.

(29) Gigli, G.; Inganäs, O.; Anni, M.; DeVittorio, M.; Cingolani, R.; Barbarella, G.; Favaretto, L. Appl. Phys. Lett. 2001, 78, 1493. moderate average luminance values on the order of 100 $\mathrm{cd} / \mathrm{m}^{2}$ are sufficient for some display applications.

The performance of organic LEDs depends on the efficiency of charge injection and charge transport as well as on the efficiency of radiative recombination of electrons and holes. Oligothiophene-S,S-dioxides are made of electron-accepting (thienyl-S,S-dioxide) and electron-donating (thienyl) groups and are consequently reversibly oxidated and reduced at moderate potential values. ${ }^{22}$ As demonstrated in recent papers (see, for example, ref 30), bipolar compounds are well-suited for LED technology, since they allow both easy hole injection and el ectron injection. Unfortunately, very little is known about the charge-transport properties of oligothiophene-S,S-dioxides and how they are affected by oligomer size. Thus, a useful development of the present research would concern the charge-transport properties of ol igothiophene-S,S-dioxides and how they affect current density and luminance of electroluminescent devices fabricated with these materials.

\section{Conclusion}

The lack of conformational flexibility of the newly synthesized oligothiophene-S,S-dioxides described in this paper drastically limits the weight of self-assembly processes and nonradiative pathways that lead to PL quenching.

The high solid-state PL efficiencies reported here (up to nearly one photon reemitted radiatively every two absorbed) are probably not yet the upper PL limit for this class of compounds. The fact that much larger PL quantum yields are measured in solution (up to two photons reemitted radiatively every three absorbed) indicates that, when the structural factors controlling the self-assembly modalities of these compounds are better known, it will be possible to program molecules with even greater solid-state PL efficiencies and PL quantum yields scarcely sensitive to environment changes.

Finally, we have shown that the new molecules are electroactive and that efficient el ectroluminescent devices can be fabricated on the basis of spin-coated thin films of these compounds.

\section{Experimental Section}

Materials. 3-Bromo-4-methylthiophene, $\mathrm{BF}_{3} \cdot \mathrm{Et}_{2} \mathrm{O}$, phenyltributylstannane, and BuLi were purchased from Aldrich. Metachloroperoxybenzoic acid (MCPBA), N-bromosuccinimide (NBS), and $\mathrm{H}_{2} \mathrm{O}_{2}$ were purchased from Fluka, Lancaster, and Carlo E rba, respectively. $\mathrm{Pd}\left(\mathrm{AsPh}_{3}\right)_{4}$ was prepared in situ from tris(dibenzylideneacetone)dipal ladium(0)-chloroform adduct (Aldrich) and $\mathrm{AsPh}_{3}$ (Aldrich). ${ }^{7 d}$

The synthesis of [3,2-b:2, 3'-d]dithienothiophene-S,Sdioxide (1) has already been described. ${ }^{9}$

3,5-Dimethyldithieno[3,2-b;2' ,3'-d]thiophene (1c). To a solution containing $8.7 \mathrm{~g}(0.05 \mathrm{~mol})$ of 3-bromo-4-methylthiophene (1a) in $50 \mathrm{~mL}$ of anhydrous ethyl ether at $\mathrm{T}=-70$ ${ }^{\circ} \mathrm{C}$ was added dropwise $19.6 \mathrm{~mL}(0.049 \mathrm{~mol})$ of $2.5 \mathrm{M} \mathrm{BuLi}$ in hexane, and the mixture stirred for $1 \mathrm{~h}$. Then $7.8 \mathrm{~g}(0.0248$ $\mathrm{mol})$ of $\mathrm{Ph}\left(\mathrm{SO}_{2}\right)_{2} \mathrm{~S}$ was added stepwise and the solution stirred overnight at room temperature. Afterward, $5 \mathrm{~mL}$ of $\mathrm{H}_{2} \mathrm{O}$ was added, the mixture was filtered and washed with ethyl ether, and the organic layer was separated, dried over $\mathrm{Na}_{2} \mathrm{SO}_{4}$, and

(30) Shirota, Y.; Kinoshita, M.; Noda, T.; Okumoto, K.; Ohara, T. J. Am. Chem. Soc. 2000, 122, 11021. 
chromatographed on silica gel using petroleum ether 40/70. A yellow oil (1b, $2.83 \mathrm{~g}, 50 \%$ yield) was obtained. To a solution containing $1.0 \mathrm{~g}$ of $\mathbf{1 b}(0.0044 \mathrm{~mol})$ in $15 \mathrm{~mL}$ of anydrous ethyl ether was added dropwise $3.5 \mathrm{~mL}(0.0088 \mathrm{~mol})$ of $2.5 \mathrm{M} \mathrm{BuLi}$ in hexane, and the solution refluxed for $3 \mathrm{~h}$. The solution was then cooled at $\mathrm{T}=0{ }^{\circ} \mathrm{C}$ and transferred dropwise to a vessel containing $1.34 \mathrm{~g}(0.01 \mathrm{~mol})$ of anhydrous $\mathrm{CuCl}_{2}$ in $5 \mathrm{~mL}$ of ethyl ether at $\mathrm{T}=0{ }^{\circ} \mathrm{C}$. The mixture was stirred for $30 \mathrm{~min}$ at $\mathrm{T}=0{ }^{\circ} \mathrm{C}$ and then allowed to raise to room temperature and stirred overnight. Afterward, $20 \mathrm{~mL}$ of water was added, the mixture was filtered and washed with ethyl ether, and the organic layer was separated, dried over $\mathrm{Na}_{2} \mathrm{SO}_{2}$, evaporated, and chromatographed on $\mathrm{Al}_{2} \mathrm{O}_{3}$ using hexane as the eluant. $\mathrm{A}$ white crystal line product $(0.6 \mathrm{~g}, 60 \%$ yiel d) was obtained. $\mathrm{Mp}$ : $93^{\circ} \mathrm{C}$. MS $(70 \mathrm{eV}, \mathrm{EI}): \mathrm{m} / \mathrm{e} 224\left(\mathrm{M}^{\circ}+\right) \cdot \lambda_{\max }\left(\mathrm{CH}_{2} \mathrm{Cl}_{2}\right)=294 \mathrm{~nm}$. ${ }^{1} \mathrm{H} \mathrm{NMR}\left(\mathrm{CDCl}_{3}\right): \delta \mathrm{ppm}=6.948(2 \mathrm{H}, \mathrm{q}, \mathrm{J}=1.0 \mathrm{~Hz}), 2.385$ $(6 \mathrm{H}, \mathrm{d}, \mathrm{J}=1.0 \mathrm{~Hz}) .{ }^{13} \mathrm{C} \mathrm{NMR}\left(\mathrm{CDCl}_{3}\right): \delta \mathrm{ppm}=142.6,131.2$, 131.0, 121.0, 14.9. Anal. Calcd for $\mathrm{C}_{10} \mathrm{H}_{8} \mathrm{~S}_{3}$ : C, 53.53; H, 3.59. Found: C, 53.41; $\mathrm{H}, 3.58$.

3,5-Dimethyldithieno[3,2-b;2',3'-d]thiophene-4,4-dioxide (2). To a solution containing $0.32 \mathrm{~g}(0.00143 \mathrm{~mol})$ of $\mathbf{1 c}$ in $22 \mathrm{~mL}$ of acetic acid and $2 \mathrm{~mL}$ of $\mathrm{CH}_{2} \mathrm{Cl}_{2}$ was added dropwise $4.3 \mathrm{~mL}$ of $\mathrm{H}_{2} \mathrm{O}_{2}(30 \%)$ at room temperature and the mixture stirred overnight. Then $20 \mathrm{~mL}$ of methylene chloride was added, and the solution was washed twice with $20 \mathrm{~mL}$ of $10 \%$ $\mathrm{KOH}$ and twice with $20 \mathrm{~mL}$ of $10 \% \mathrm{NaHCO}_{3}$. Afterward, the mixture was washed with water, and the organic layer was separated, dried over $\mathrm{Na}_{2} \mathrm{SO}_{4}$, and chromatographed on silica gel using hexane: ethyl acetate:methylene chloride 80:10:10 as eluent. A yellow crystalline product $(0.134 \mathrm{~g}, 36 \%$ yield) was obtained. Mp: $197^{\circ} \mathrm{C}$. MS (70 eV, El): m/e $256\left(\mathrm{M}^{\circ+}\right) . \lambda_{\max }$ $\left(\mathrm{CH}_{2} \mathrm{Cl}_{2}\right)=364 \mathrm{~nm} .{ }^{1} \mathrm{H} \mathrm{NMR}\left(\mathrm{CDCl}_{3}\right): \delta \mathrm{ppm}=6.878(2 \mathrm{H}, \mathrm{q}$, $\mathrm{J}=1.0 \mathrm{~Hz}), 2.414(6 \mathrm{H}, \mathrm{d}, \mathrm{J}=1.0 \mathrm{~Hz}) .{ }^{13} \mathrm{C} \mathrm{NMR}\left(\mathrm{CDCl}_{3}\right): \delta$ $\mathrm{ppm}=142.7,135.8,133.0,124.6,13.1$. Anal. Calcd for $\mathrm{C}_{10} \mathrm{H}_{8} \mathrm{O}_{2} \mathrm{~S}_{3}: \mathrm{C}$, 46.85; $\mathrm{H}, 3.15$. Found: $\mathrm{C}, 46.91 ; \mathrm{H}, 3.14$.

3,5-Dimethyldithieno[3,2-b;2,3-d]thiophene-4-oxide (3). To a solution containing $0.28 \mathrm{~g}(0.00125 \mathrm{~mol})$ of $\mathbf{1 c}$ in $10 \mathrm{~mL}$ of anydrous $\mathrm{CH}_{2} \mathrm{Cl}_{2}$ at $\mathrm{T}=-20^{\circ} \mathrm{C}$ was added dropwise $0.53 \mathrm{~g}$ $(0.00375 \mathrm{~mol})$ of $\mathrm{BF}_{3^{\circ}} \mathrm{Et}_{2} \mathrm{O}$. After $10 \mathrm{~min}$ a solution containing $0.37 \mathrm{~g}(0.0015 \mathrm{~mol})$ of MCPBA (70\%) in $5 \mathrm{~mL}$ of anydrous methylene chloride was added dropwise and the mixture stirred for $2 \mathrm{~h}$ at $\mathrm{T}=-20^{\circ} \mathrm{C}$. Then the solution was allowed to reach ambient temperature, $20 \mathrm{~mL}$ of saturated $\mathrm{NaHSO}_{3}$ was added, and the organic layer was separated, washed first with $20 \mathrm{~mL}$ of saturated $\mathrm{NaHCO}_{3}$ and then with water, dried over $\mathrm{Na}_{2} \mathrm{SO}_{4}$, and chromatographed on silica gel using pentane: methylene chloride: ethyl acetate $70: 15: 15$ as eluent. A crystalline yellow solid $(0.163 \mathrm{~g}, 54 \%$ yield) was obtained. Mp: $142{ }^{\circ} \mathrm{C}$. MS $(70 \mathrm{eV}, \mathrm{EI}): \mathrm{m} / \mathrm{e} 240\left(\mathrm{M}^{\circ}\right) \cdot \lambda_{\max }\left(\mathrm{CH}_{2} \mathrm{Cl}_{2}\right)=$ $374 \mathrm{~nm} .{ }^{1} \mathrm{H}$ NMR $\left(\mathrm{CDCl}_{3}\right): \delta \mathrm{ppm}=6.8765(2 \mathrm{H}, \mathrm{q}, \mathrm{J}=1.0$ $\mathrm{Hz}), 2.4559(6 \mathrm{H}, \mathrm{d}, \mathrm{J}=1.0 \mathrm{~Hz}) \cdot{ }^{13} \mathrm{C} \mathrm{NMR}\left(\mathrm{CDCl}_{3}\right): \delta \mathrm{ppm}=$ 149.3, 138.3, 135.6, 123.3, 13.6. Anal. Calcd for $\mathrm{C}_{10} \mathrm{H}_{8} \mathrm{OS}_{3}$ : C, 49.97; H, 3.35. Found: $\mathrm{C}, 49.82 ; \mathrm{H}, 3.37$.

3,5-Dimethyl-2,3'-bis(3-methylthiophene)dithieno[3,2b;2, 3'-d]thiophene-4,4-dioxide (5). To a solution of $0.13 \mathrm{~g}$ ( $0.0005 \mathrm{~mol}$ ) of $\mathbf{2}$ in $15 \mathrm{~mL}$ of acetic acid: $\mathrm{CH}_{2} \mathrm{Cl}_{2} \mathrm{l}: 1$ was added stepwise $0.25 \mathrm{~g}(0.0014 \mathrm{~mol})$ of NBS at $\mathrm{T}=0{ }^{\circ} \mathrm{C}$. The mixture was stirred overnight, then $50 \mathrm{~mL}$ of methylene chloride was added, the mixture was washed with $100 \mathrm{~mL} 10 \% \mathrm{KOH}$, and the organic layer separated, washed with $100 \mathrm{~mL}$ of $10 \%$ $\mathrm{NaHCO}_{3}$ and then with water, dried over $\mathrm{Na}_{2} \mathrm{SO}_{4}$, evaporated, and chromatographed on silica gel using petroleum ether 30/ 40: $\mathrm{CH}_{2} \mathrm{Cl}_{2}$ :ethyl acetate 80:10:10 as eluent. A yellow solid (mp $\left.242{ }^{\circ} \mathrm{C}\right)$ was obtained $(0.173 \mathrm{~g}, 84 \%$ yield) corresponding to the $\alpha, \omega$-dibromo derivative of $\mathbf{2}$. Compound $2(0.17 \mathrm{~g}, 0.0004 \mathrm{~mol})$ was dissolved in $15 \mathrm{~mL}$ of anydrous toluene, and the solution was added dropwise to $15 \mathrm{~mL}$ of anhydrous toluene containing $0.038 \mathrm{mmol}$ of $\mathrm{Pd}\left(\mathrm{AsPh}_{3}\right)_{4}$ prepared in situ. ${ }^{7 d}$ At reflux, $0.33 \mathrm{~g}$ $(0.00085 \mathrm{~mol})$ of 2-tributylstannyl-3-methylthiophene ${ }^{7 a}$ was added dropwise and the mixture refluxed for about $5 \mathrm{~h}$. Afterward, the mixture as such was evaporated and chromatographed on silica gel using pentane:methylene chloride:ethyl acetate $90: 5: 5$ as eluent to yield a yellow solid $(5,0.143 \mathrm{~g}, 80 \%)$. Mp: $142{ }^{\circ} \mathrm{C}$. MS $(70 \mathrm{eV}, \mathrm{EI}): \mathrm{m} / \mathrm{e} 448\left(\mathrm{M}^{+}\right) \cdot \lambda_{\max }\left(\mathrm{CH}_{2} \mathrm{Cl}_{2}\right)=$ $404 \mathrm{~nm} .{ }^{1} \mathrm{H} \mathrm{NMR}\left(\mathrm{CDCl}_{3}\right): \delta \mathrm{ppm}=7.35(2 \mathrm{H}, \mathrm{d}, \mathrm{J} \mathrm{AB}=5.0$
$\mathrm{Hz}), 6.96(2 \mathrm{H}, \mathrm{d}, \mathrm{J} A B=5.0 \mathrm{~Hz}), 2.34(6 \mathrm{H}, \mathrm{s}), 2.22(6 \mathrm{H}, \mathrm{s}) .{ }^{13} \mathrm{C}$ NMR $\left(\mathrm{CDCl}_{3}\right): \delta \mathrm{ppm}=142.0,138.3,134.6,134.5,131.5$, 130.4, 126.7, 126.6, 14.8, 12.2. Anal. Calcd for $\mathrm{C}_{20} \mathrm{H}_{16} \mathrm{O}_{2} \mathrm{~S}_{5}$ : C, 53.54; H, 3.59. Found: C, 53.61; H, 3.60.

3,5-Dimethyl-2,3'-bis(3-methylthiophene)dithieno[3,2b;2',3'-d]thiophene-4,4-dioxide (6) was prepared according to the same modalities as $\mathbf{5}$ using a $0.068 \mathrm{~g}$ of the $\alpha, \omega$-di bromo derivative of $2(0.000166 \mathrm{~mol}), 0.0166 \mathrm{mmol}$ of $\mathrm{Pd}\left(\mathrm{AsPh}_{3}\right)_{4}$ prepared in situ, and $0.139 \mathrm{~g}(0.00038 \mathrm{~mol})$ of phenyltributylstannane in $25 \mathrm{~mL}$ of toluene. A yellow solid $(0.048 \mathrm{~g}, 70 \%$ yield) was obtained. Mp: $199{ }^{\circ} \mathrm{C}$. MS (70 eV, El): m/e408 $\left(\mathrm{M}^{\circ}+\right.$ ). $\lambda_{\max }\left(\mathrm{CH}_{2} \mathrm{Cl}_{2}\right)=403 \mathrm{~nm}$. ${ }^{1 \mathrm{H}} \mathrm{NMR}\left(\mathrm{CDCl}_{3}\right): \delta \mathrm{ppm}=7.44(10 \mathrm{H}$ $\mathrm{m}), 2.48(6 \mathrm{H}, \mathrm{s}) .{ }^{13} \mathrm{C}$ NMR $\left(\mathrm{CDCl}_{3}\right): \delta \mathrm{ppm}=142.79,142.78$, $133.1,132.6,128.97,128.8,128.6,128.3,12.3$. Anal. Calcd for $\mathrm{C}_{22} \mathrm{H}_{16} \mathrm{O}_{2} \mathrm{~S}_{3}: \mathrm{C}, 64.68 ; \mathrm{H}, 3.95$. Found: $\mathrm{C}, 64.51 ; \mathrm{H}, 3.97$.

X-ray Crystallography. Crystals suitable for X-ray analysis were grown by slow evaporation from chl oroform solutions. All X-ray measurements were carried out at room temperature on a Enraf-Nonius CAD4 diffractometer by using graphitemonochromated Mo $\mathrm{K} \alpha$ radiation. In all cases, unit cell parameters were derived from least-squares fit to setting angles of 25 automatically centered reflections from various regions of reciprocal space. For all crystals, the intensities were corrected for Lorentz and polarization effects, and absorption corrections, based on an empirical $\psi$ scan, were applied to data. ${ }^{32}$ All structures were solved by direct methods (SHELX86 program) and were refined through full-matrix leastsquares calculations based on $\mathrm{F}^{2}$ (SHEXL-93 program) using all unique reflections. ${ }^{33,34}$ In all cases, non-hydrogen atoms were refined anisotropically and $\mathrm{H}$ atoms, located in $\Delta \mathrm{F}$ maps, isotropically (with equal B for $\mathrm{H}$ bonded to the same $\mathrm{C}$ atom). Details of data collection and processing are reported in Table 2.

Photo- and E lectroluminescence. Optical measurements were performed on microcrystalline powders by exciting the sample with an Ar ion laser $\left(\lambda_{\text {exc }}=363 \mathrm{~nm}\right)$ and collecting the spatially averaged PL with a charge coupled device (CCD) spectrograph. The PL efficiency measurements were carried out by means of an integrating sphere. ${ }^{34}$ Absorption spectra were recorded with a Hewlett-Packard CCD spectrophotometer. The electrol uminescent diode reported in Figure 4 was prepared by spin coating onto indium-tin oxide (ITO) glass first poly(3,4-ethylene dioxythiophene) (PEDOT) doped with poly(styrene sulfonate), and then a chloroform solution of the pure active material. The estimated PL quantum yield of the film was on the order of that of the microcrystalline powder. The cathodes (Ca followed by Al cap) were deposited by thermal evaporation. Device characterization was carried out in an air atmosphere.

Computational Methods. Ab initio calculations were carried out at the B3LYP/6-31G* level for the ground state and at the $\mathrm{CIS}$ (direct)/6-31G* level for the first excited state using the Gaussian98 series of programs. ${ }^{35}$ Geometries were fully optimized by standard gradient techniques and the final minima were checked by frequency analysis. Optimized coor-

(31) North, A. C. T.; Phillips Mathews, M. C. Acta Crystallogr Sect.A, 1968, 24, 351

(32) Sheldrick, G. M. Acta Crystallogr. Sect. A, 1990, 46, 467.

(33) Sheldrick, G. M. SHELXL-93: Program for the refinement of crystal structures; University of Göttingen: Göttingen, Germany, 1993.

(34) De Mello, J . C.; Wittmann, H. F.; Friend, R. H. Adv. Mater. $1997,9,230$

(35) Frisch, M. J .; Trucks, G. W.; Schlegel, H. B.; Scuseria, G. E.; Robb, M. A.; Cheeseman, J. R.; Zakrzewski, V. G.; Montgomery, J. A.; Stratmann, R. E.; Burant, J . C.; Dapprich, S.; Millam, J. M.; Daniels A. D.; Kudin, K. N.; Strain, M. C.; Farkas, O.; Tomasi, J .; Barone, V.; Cossi, M.; Cammi, R.; Mennucci, B.; Pomelli, B.; Adamo, C.; Clifford, S.; Ochterski, J .; Petersson, G. A.; Ayala, P. Y.; Cui, Q.; Morokuma, K.; Malick, D. K.; Rabuck, A. D.; Raghavachari, K.; Foresman, J . B.; Cioslowski, J .; Ortiz, J. V.; Baboul, G.; Stefanov, B. B.; Liu, G.; Liashenko, A.; Piskorz, P.; Komaromi, I.; Gomperts, R.; Martin, R. L.; Fox, D. J .; Keith, T.; Al-Laham, M. A.; Peng, C. Y.; Nanayakkara, A.; Gonzalez, C.; Challacombe, M.; Gill, P. M. W.; J ohnson, B.; Chen, W.; Wong, M. W.; Andres, J . L.; Gonzalez, C.; Head-Gordon, M.; Replogle, E. S.; PopleJ . A. Gaussian 98, Revision A.7; Gaussian, Inc.: Pittsburgh, PA, 1998. 
dinates are reported as Supporting Information. UV transitions were calculated by $\mathrm{ZINDO} / \mathrm{S}-\mathrm{Cl}(6 \times 6)$ single point calculations on ab initio geometries using HyperChem integrated package. ${ }^{36}$

Acknowledgment. The present work was partially supported by the project "Nuovi emettitori di luce a semiconduttore organico" (CNR-5\% Nanotecnologie)

(36) HyperChem rel 5.1; HyperCube: Waterloo, Ontario, Canada.
Supporting Information Available: Tables of positional and thermal parameters, bond distances and angles, torsion angles, shortest nonbonded distances, selected least-squares planes, and stereoviews of the crystal packing; tables of optimized Cartesian coordinates and energies of the ground and first excited state of compounds $\mathbf{1}$ and $\mathbf{2}$ and optimized Cartesian coordinates and energies of the pyramidal ground state and the planar transition state of compound $\mathbf{3}$ (PDF). This material is available free of charge via the Internet at http://pubs.acs.org.

CM $010436 \mathrm{~T}$ 